\title{
Developing a Virtual Group Decision Support System Based on Fuzzy Hybrid MCDM Approach
}

\author{
Bahram Izadi \\ Department of Management, Faculty of Administrative Sciences and economics, University of Isfahan, IRAN \\ izady.bahram@gmail.com \\ Saeedeh Ketabi \\ Department of Management, Faculty of Administrative Sciences and economics, University of Isfahan, IRAN \\ s.ketabi@yahoo.com
}

\begin{abstract}
Organizational decisions involve with unusually vague and conflicting criteria. This controversy increases empirical uncertainties, disputes, and the resulting consequences of these decisions. One possible method in subduing this problem is to apply quantitative approaches to provide a transparent process for resolute conclusions which enables decision makers to formulate accurate and decisive on time decisions. Although numerous methods are presented in the literature, the majority of them aim to develop theoretical models. However, this article aims to develop and implement an integrated fuzzy virtual MCDM model based on fuzzy AHP and fuzzy TOPSIS as a decision support system (DDS). Preventing disadvantageous face-to-face decision-making by achieving positive benefit from virtual decision making causes the proposed DDS to be suitable for making crucial decisions such as supplier selection, employee selection, employee appraisal, R\&D project selection, etc. The proposed DDS has been implemented in an optical company in Iran.
\end{abstract}

Index Terms - Virtual Group Decision Making; Decision Support System; MCDM

\section{Introduction}

The design and implementation of decision support systems that can introduce automation and intelligence to on-line negotiations is currently the focus of intensive research efforts. Negotiation models, however, are characterized as of relatively high complexity, since they involve evaluation and decision making in a state of uncertainty, based on multiple attributes (criteria) of quantitative and qualitative natures, involving temporal resource constraints, risk and commitment issues, varying tactics and strategies, domain specific knowledge and information asymmetries, etc [1]. On the other hand, the organizational decisions are often related to different, enormous and conflicting criteria and evaluations. For these reasons today's fast changing global environments dictate that a successful enterprise has a rich decision-making process [2].

To encounter these situations, organizations implement decision support systems (DSS) in order to change data to information, comparison of the options and outcomes, saving of cost and time, effective teamwork etc. In addition, DSS enables organizations to manage virtual group decision making in which the disadvantages of face-to-face or conventional group involvement are removed. The common group processes losses cited in the literature includes dominance of one group member, production blocking, social loafing, free-riding, cognitive inertia, and information overload [3]. In contrast, DSS advantages are improving personal efficiency, expenditure problem solving, facilitates impersonal communications; promotes comprehension and training, and increased organizational control [4]. In addition the study [5] found that greater decision acceptance and willingness to work together obtained in virtual group decision making as compared to face-to-face group decisionmaking. Other advantages are storing data, transforming data to knowledge and information, and decreasing the possibility of conspiracy.

Different approaches introduced in the literature encounter multi-criteria decision making such as Analytical Hierarchical Processes (AHP), Elimination, and Choice Expressing Reality (ELECTRE) etc. However, since [6] proposed the decision-making methods in fuzzy environments, show an increasing number of fuzzy models introduced [7]. This approach is widely used because fuzziness and vagueness are usually present in the decision-making process.

The hybrid model of this paper uses modified fuzzy AHP and fuzzy Technique for Order Preference by Similarity to Ideal Solutions (TOPSIS) in the form of decision support systems. FAHP utilizes linguistic variables expressed in triangular fuzzy numbers to 
assess weights of criteria. However, to avoid quickly increasing pair-wise comparison when alternatives are immoderate, fuzzy TOPSIS is used (instead of FAHP) to find each alternative's closeness coefficient. In addition, this hybrid model takes in different backgrounds such as experience, education, organizational rank and work history of decision makers in to consideration. The contribution of this paper is constructing a decision support tool which can manage the complicated process of decision-making in an organization effectively and easily.

This paper is organized as follows. Section 2 reviews the basic concepts and formulation of fuzzy approach. Section 3 presents the proposed method. The architecture of DDS is explained in section 4. Finally, section 5 concludes this paper with the remark of a decision support system named as Fuzzy Group Decision Making (FGDM).

\section{Methodol ogy}

\subsection{Definitions}

\subsubsection{Fuzzy Number:}

Fuzzy concept was introduced by [8] to overcome the vagueness of information. A positive triangular fuzzy number $(\mathrm{TFN})$ defined as $\tilde{A}=(l, m, u)$ shown in Figure 1 and the membership function defined as (1).

$$
\mu_{A}(x)=\left\{\begin{array}{ll}
\frac{(x-l)}{(m-l)} & \text { if } l \leq x \leq m \\
\frac{(u-x)}{(u-m)} & \text { if } m \leq x \leq u \\
0 & \text { Otherwise }
\end{array}\right\}
$$

\subsubsection{Operation on Fuzzy Numbers:}

Let $\tilde{A}$ and $\tilde{B}$ be two TFN given by $\tilde{A}=\left(l_{l}, m_{l}, u_{l}\right)$ and $\tilde{B}=\left(l_{2}, m_{2}, u_{2}\right)$ respectively and $p$ is a real positive number. Some algebraic operations of TFN are as follows:

for $l, m, u>0$ :

$\tilde{A} \oplus \tilde{B}=\left(l_{1}+l_{2}, m_{1}+m_{2}, u_{1}+u_{2}\right)$

$\tilde{A} \otimes \tilde{B}=\left(l_{1} l_{2}, m_{1} m_{2}, u_{1} u_{2}\right)$

$\tilde{A} \odot \tilde{B}=\left(l_{1}-u_{2}, m_{1}-m_{2}, u_{1}-l_{2}\right)$

$p \otimes \tilde{B}=\left(p l_{1}, p m_{1}, p u_{1}\right)$

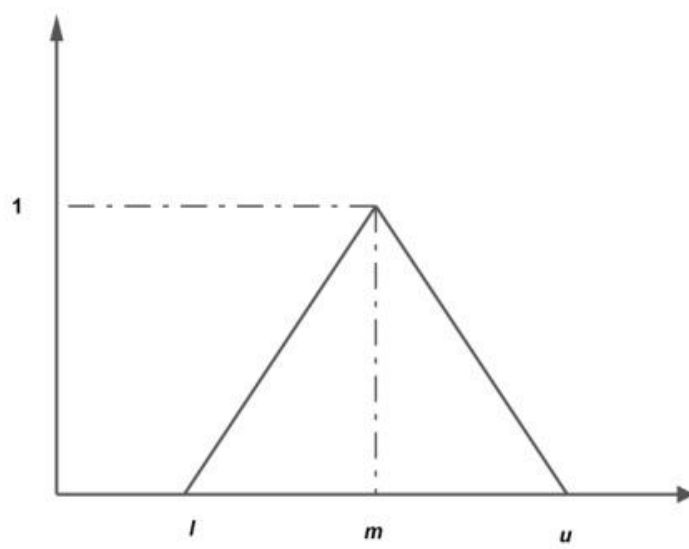

Fig 1: Triangular Fuzzy Number (TFN)

$$
\begin{aligned}
& \tilde{A} \varnothing \tilde{B}=\left(l_{1} / u_{2}, m_{1} / m_{2}, u_{1} / l_{2}\right) \\
& \tilde{A}^{-1}=\left(1 / u_{1}, 1 / m_{1}, 1 / l_{1}\right)
\end{aligned}
$$

\subsubsection{Fuzzy Distance:}

The distance between two fuzzy numbers $\tilde{A}=\left(l_{1}, m_{1}, u_{1}\right)$ and $\tilde{B}=\left(l_{2}, m_{2}, u_{2}\right)$ is calculated by 3 dimentional Euclidean distance:

$$
a(\tilde{A}, \tilde{B})=\sqrt{\frac{1}{2}\left[\left(l_{1}-l_{2}\right)^{2}+\left(m_{1}-m_{2}\right)^{2}+\left(u_{1}-u_{2}\right)^{2}\right.}
$$

\subsubsection{Linguistic Variables:}

Linguistic variables are variables whose values are words or sentences in a natural or artificial language [9]. In this paper, decision makers use linguistic variables shown in table 1 , to evaluate the importance of criteria, and Table 2 for rating the alternatives with respect to each criterion.

Table 1: Membership functions of the seven levels of linguistic variables for rating alternatives

\begin{tabular}{llll}
\hline $\begin{array}{c}\text { Fuzzy } \\
\text { Number }\end{array}$ & Linguistic Scales & TFN & TFN Reciprocal \\
\hline$\tilde{9}$ & $\begin{array}{l}\text { Absolutely } \\
\text { important }\end{array}$ & $(7,9,9)$ & $(1 / 9,1 / 9.1 / 7)$ \\
$\tilde{7}$ & $\begin{array}{l}\text { Very strongly } \\
\text { important }\end{array}$ & $(5,7,9)$ & $(1 / 9,1 / 7,1 / 5)$ \\
$\tilde{5}$ & $\begin{array}{l}\text { Essentially } \\
\text { important }\end{array}$ & $(3,5,7)$ & $(1 / 7,1 / 5.1 / 3)$ \\
$\tilde{3}$ & Weakly important & $(1,3,5)$ & $(1 / 5,1 / 3,1)$ \\
$\tilde{1}$ & & & \\
$\tilde{2}, \tilde{4}, \tilde{6}, \tilde{8}$ & Equally important & $(1,1,3)$ & $(1 / 3,1,1)$ \\
\hline
\end{tabular}


Table 2: Membership functions of the seven levels of linguistic variables for rating alternatives

\begin{tabular}{lll}
\hline $\begin{array}{c}\text { Fuzzy } \\
\text { Number }\end{array}$ & \multicolumn{1}{c}{ Linguistic Scales } & TFN \\
\hline$\tilde{10}$ & Very Good & $(9,10,10)$ \\
$\tilde{9}$ & Good & $(8,9,10)$ \\
$\tilde{7}$ & Relatively Good & $(6,7,8)$ \\
$\tilde{5}$ & Moderate & $(4,5,6)$ \\
$\tilde{3}$ & Relatively Week & $(2,3,4)$ \\
$\tilde{1}$ & Week & $(0,1,2)$ \\
$\tilde{0}$ & Very Week & $(0,0,1)$ \\
$\tilde{2}, \tilde{4}, \tilde{6}, \tilde{8}$ & Intermediate value between & two adjacent \\
\hline
\end{tabular}

\subsection{Fuzzy Analytic Hierarchical Process:}

AHP introduced by [10] allows for the application of data, experience, insight, and intuition in a logical and thorough way. However, the AHP method does not take into account the uncertainty associated with the mapping while the AHP's subjective assessment, selection and preference of decision-makers have great influence in the success of the method [11]. Decisionmakers usually find that it is more accurate to give interval assessments rather than fixed value merit. [12] Therefore, based on a fu zzy paradig $m$ introduced by [8], fuzzy AHP is used in which local and global priorities from fuzzy preference ratios are derived. We derive fuzzy weight of pair-wise matrix elements by calculating the matrix eigenvalues according to (9) [13].

$$
S_{k}=\sum_{j=1}^{n} M_{k l} \times\left[\sum_{i=1}^{m} \sum_{j=1}^{n} M_{i j}\right]^{-1}
$$

where $M$ is triangular fuzzy number and $k, i$ and $j$ represent matrix row, alternatives and criteria respectively.

\section{Proposed Method}

A decision support system named as Fuzzy Group Decision Making (FGDM) is programmed to utilize fuzzy AHP and TOPSIS. Figure 2 indicates the flow diagram of the system. Let's suppose a virtual decisionmaking committee with $k$ members who intend to rank $i$ alternatives with respect to $j$ criteria. The administrator is responsible for selection of best alternative.

\subsection{Data Input}

1) FGDM includes three databases: Criteria, Alternatives and Decision makers. The manager $\log$ s on to the system, sets a new project name, chooses decision-makers and sets username and password for each one. Now each member can access to the system to assess the importance of criteria and rate each criterion with respect to the alternatives.

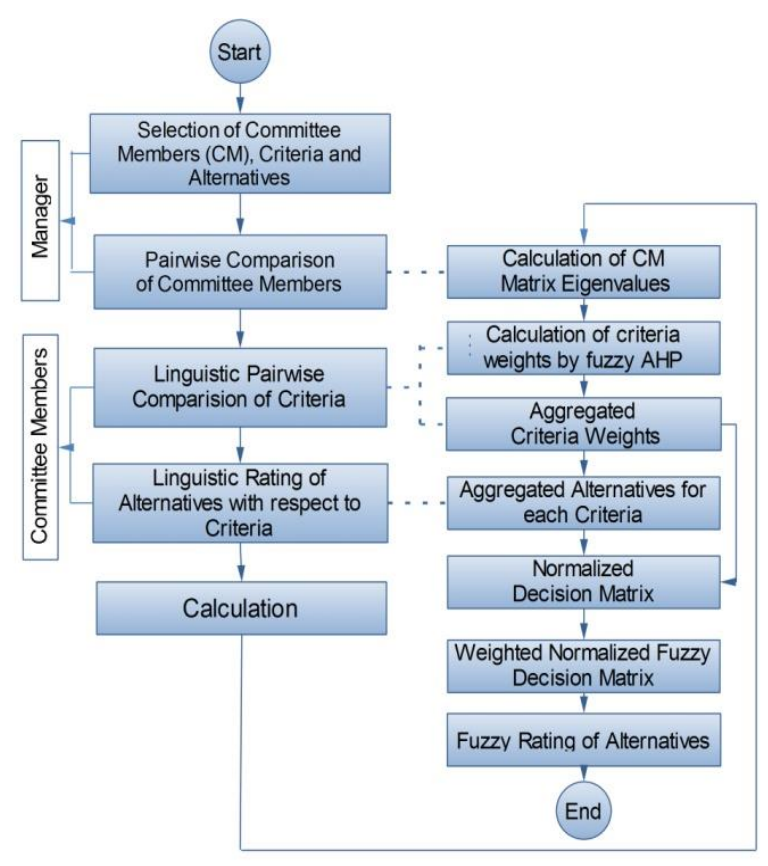

Fig. 2: The steps of problem formulation and calculation

2) The decision-makers naturally have different backgrounds such as educational achievement, job history and organizational status. Therefore, it is expected that these factors may affect their final assessments. Take in these factors in to consideration, the manager uses pair-wise comparisons between his team members based on correspondence circulated to different departments and it is establishing a base for appraisal evaluation objectives as well. Some methods have been introduced to weight decision-makers. For instance, [14] suggested the use of interpersonal comparison to obtain the values of scaling constants in the weighted additive social choice function. This weighting will be used in further calculations.

3) Based on these comparisons, the weighting factors of members according to (10) are calculated and stored in memory [10]:

$$
w=\lim _{k \rightarrow \infty} \frac{D M^{k} \cdot e}{e^{T} D M^{k} \cdot e}
$$

in which $e^{T}=(1,1,1, \ldots, 1)$ and $D M$ is comparison matrix of decision-makers. When the difference between $D M^{k}$ and $D M^{k+1}$ can be neglected the computation is stopped and the data stored in a weighting vector:

$$
D=\left(D_{1}, D_{2}, \ldots, D_{k}\right)
$$


4) Choosing the adequate criteria is the next step which is based on a decision disposition. There are no limitations in criteria and alternatives selection. However, increasing the number of selections raises the inconsistency of pair-wise comparison in further steps.

5) Another step is alternative (for instance, supplier) selection. Figure 3 indicates the selection window of criteria, alternatives and decision makers.

6) Now each member log on to FGDM and assess the importance of the criteria and rate alternatives with respect to criterion in two adjacent questionnaires. There is a pull-down menu in the first questionnaire to facilitate the comparison and a seven-point scale (checklist) in the second one to rate the alternatives linguistically. Less uncertainty becomes the advantage of paired-comparison for individuals; it is more of a convenience than an absolute comparison [15]. Table 3 indicates the assessment of the importance of criteria by two typical users. It is seen that these two people have different ideas for the importance of criteria. While the first believes that the importance of $C_{1}$ against $C_{4}$ is low, the other sees it as "absolutely high". These decision makers come from different organizational departments. When two or more organizational departments strive for mutually acceptable purchase choices or attempts to agree on an issue such as product specification and vendor capabilities, a potential conflict becomes present [16].

\subsection{Calculation}

1) When the members fulfilled their assessments, the manager logs on to the system in order to calculate the results.

2) The linguistic variables are transformed to their equivalent fuzzy numbers by the scale indicated in Table 1 and 2 and weighted variables are calculated using (11). Suppose $p=1, \ldots, k$ decision makers believe the importance of $j=1, \ldots, n$ criteria as those indicated in Table 4 in which $w_{j k}$ is a triangular fuzzy number [17].

3) In order to aggregate fuzzy weights of each criterion, we use the following method:

$$
\begin{gathered}
\tilde{w}_{j k}=\left(w_{1}, w_{2}, w_{3}\right) \\
\sim_{j}=\left(w_{j 1}, w_{j 2}, w_{j 3}\right)
\end{gathered}
$$

in which

$$
\begin{aligned}
& w_{j 1}=\min _{k}\left\{w_{j k 1}\right\}, \\
& w_{j 2}=\frac{1}{k} \sum_{j=1}^{k} w_{j k 2}, \\
& w_{j 3}=\max _{k}\left\{w_{j k 3}\right\}
\end{aligned}
$$

4) The second questionnaire is the rating of alternatives with respect to each criterion indicated in Table 5 in which $\tilde{r}_{j i p}$ is a fuzzy triangular number:

$$
\tilde{r}_{j i p}=\left(a_{n m k}, b_{n m k}, c_{n m k}\right)
$$

The aggregate fuzzy rating of alternatives on various criteria can be calculated as follows:

$$
\tilde{r}_{j i}=\left(a_{n m}, b_{n m}, c_{n m}\right)
$$

in which

$$
\begin{aligned}
& a_{n m}=\min _{i}\left\{a_{n m k}\right\}, \\
& b_{n m}=\frac{1}{k} \sum_{k=1}^{K} b_{n m k}, \\
& c_{n m}=\max _{k}\left\{c_{n m k}\right\}
\end{aligned}
$$

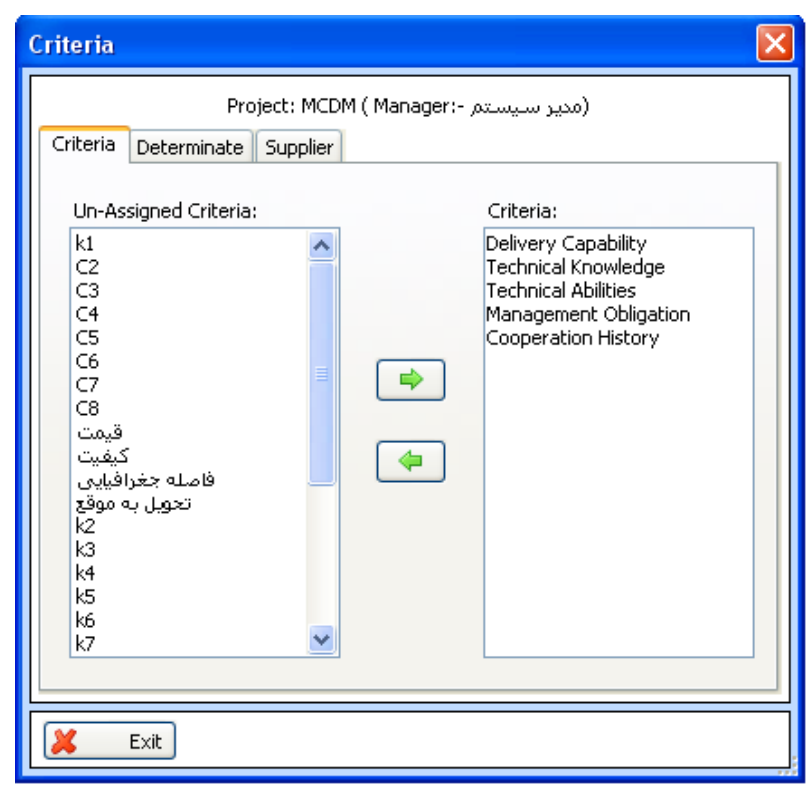

Fig. 3: Selection of criteria, alternatives and decision makers 
Table 3: The importance of criteria assessed by two people

\begin{tabular}{cccccc}
\hline$D_{1}$ & $C_{1}$ & $C_{2}$ & $C_{3}$ & $C_{4}$ & Low \\
\hline$C_{1}$ & Equal & Equal & Low & Low & \\
\hline$D_{5}$ & $C_{1}$ & $C_{2}$ & $C_{3}$ & $C_{4}$ & $C_{5}$ \\
\hline$C_{1}$ & Equal & Relatively High & High & Absolutely High & Absolutely High \\
\hline
\end{tabular}

Table 4: The weight of $n$ criteria

\begin{tabular}{ccccc}
\hline $\boldsymbol{C}_{\boldsymbol{n}} / \boldsymbol{D}_{\boldsymbol{p}}$ & $\boldsymbol{D}_{\boldsymbol{I}}$ & $\boldsymbol{D}_{2}$ & $\ldots \ldots \ldots$ & $\boldsymbol{D}_{\boldsymbol{k}}$ \\
\hline $\boldsymbol{C}_{\boldsymbol{I}}$ & $\mathrm{w}_{11}$ & $\mathrm{w}_{12}$ & $\ldots \ldots \ldots$ & $\mathrm{w}_{1 \mathrm{k}}$ \\
$\boldsymbol{C}_{\boldsymbol{n}}$ & $\mathrm{w}_{\mathrm{j} 1}$ & $\mathrm{w}_{\mathrm{j} 1}$ & $\ldots \ldots \ldots$ & $\mathrm{w}_{\mathrm{jk}}$ \\
\hline
\end{tabular}

Table 5: Rating of $\mathrm{m}$ alternatives by $\mathrm{k}$ decision makers

\begin{tabular}{|c|c|c|c|c|c|}
\hline \multirow{2}{*}{ Criteria } & \multirow{2}{*}{ Supplier } & \multicolumn{4}{|c|}{ Decision Makers } \\
\hline & & $D_{1}$ & $D_{2}$ & ........ & $D_{k}$ \\
\hline \multirow{4}{*}{$C_{1}$} & $\mathrm{~S}_{1}$ & $\mathrm{r}_{111}$ & $\mathrm{r}_{112}$ & & $\mathrm{r}_{11 \mathrm{k}}$ \\
\hline & $\mathrm{S}_{2}$ & $\mathrm{r}_{121}$ & $\mathrm{r}_{122}$ & & $\mathrm{r}_{12 \mathrm{k}}$ \\
\hline & $\ldots$ & $\ldots$ & $\ldots$ & & $\ldots$ \\
\hline & $\mathrm{S}_{\mathrm{m}}$ & $\mathrm{r}_{1 \mathrm{ml}}$ & $\mathrm{r}_{1 \mathrm{~m} 2}$ & & $r_{1 \mathrm{mk}}$ \\
\hline \multirow{4}{*}{$C_{n}$} & $\mathrm{~S}_{1}$ & $\mathrm{r}_{\mathrm{n} 11}$ & $r_{n 12}$ & & $r_{n 1 k}$ \\
\hline & $\mathrm{S}_{2}$ & $r_{n 21}$ & $r_{n 22}$ & & $r_{n 2 k}$ \\
\hline & $\ldots$ & $\ldots \ldots$ & $\ldots \ldots$ & & $\ldots \ldots$ \\
\hline & $\mathrm{S}_{\mathrm{m}}$ & $\mathrm{r}_{\mathrm{nml}}$ & $\mathrm{r}_{\mathrm{nm} 2}$ & & $\mathrm{r}_{\mathrm{nmk}}$ \\
\hline
\end{tabular}

Table 6: Fuzzy Decision Matrix

\begin{tabular}{ccccc}
\hline Alternatives & \multicolumn{3}{c}{ Criteria } \\
\cline { 2 - 5 } & $\mathbf{C}_{\mathbf{1}}$ & $\mathbf{C}_{2}$ & $\ldots \ldots \ldots$ & $\mathbf{C}_{\mathbf{n}}$ \\
\hline $\mathbf{S}_{\mathbf{1}}$ & $\tilde{r}_{11}$ & $\tilde{r}_{12}$ & $\tilde{r}_{1 n}$ \\
$\mathbf{S}_{\mathbf{m}}$ & $\tilde{r}_{m 1}$ & $\tilde{r}_{m 2}$ & $\ldots \ldots \ldots$ & $\tilde{r}_{m n}$ \\
\hline
\end{tabular}

The new decision matrix illustrated in Table 6.

5) The scale of criteria could be different and to avoid complexity in calculations, the linear scale transformation is used to transform different criteria scales in to comparable scales. The normalized decision matrix can be expressed as

$$
\tilde{R}=\left[\tilde{r}_{i j}\right]_{m \times n}
$$

The criteria itself could be benefits or costs. We denote the set of benefit criteria as $B$ and the set of cost criteria as $C$. Then

$$
\tilde{r}_{i j}=\left(\frac{a_{i j}}{c_{j}^{*}}, \frac{b_{i j}}{c_{j}^{*}}, \frac{c_{i j}}{c_{j}^{*}}\right)
$$

in which

$$
c_{j}^{*}=\max _{i} c_{i j}, j \in B
$$

and

$$
\tilde{r}_{i j}=\left(\frac{a_{i}^{-}}{c_{i j}}, \frac{a_{i}^{-}}{b_{i j}}, \frac{a_{i}^{-}}{a_{i j}}\right)
$$

in which

$$
a_{i}^{-}=\max _{i} a_{i j}, j \in C
$$

6) Now the product of normalized decision matrix and aggregate fuzzy weights of each criterion is obtained in order to calculate the weighted normalized fuzzy decision matrix $\tilde{V}$ 


$$
\begin{gathered}
\tilde{V}=\left[v_{i j}\right]_{m \times n}, \mathrm{i}=1, . ., \mathrm{m}, \mathrm{j}=1, \ldots, \mathrm{n} \\
\tilde{v}_{i j}=r_{i j} \cdot \tilde{w}_{j}
\end{gathered}
$$

7) There are two solutions: positive and negative ideal solution results. If we consider the objective space of the two criteria $C_{1}$ and $C_{2}$ as indicated in Figure $4, A^{+}$is the positive ideal solution, $A^{-}$is the negative ideal solution, $S_{1}$ and $S_{2}$ different alternatives, $d_{1}{ }^{*}$ and $d_{1}{ }^{-}$the distance between $S_{1}$ to positive and negative ideal solution, $d_{2}{ }^{*}$ and $d_{2}{ }^{-}$the distance between $S_{2}$ to positive and negative ideal solutions. As in Figure 4 the relative distance between positive ideal solution $A^{*}$ and $S_{1}$ are shorter than $S_{2}$, therefore, the ranking of $S_{1}$ is preferred as opposed to $S_{2}$ [18]. The fuzzy positive-ideal solution $\left(A^{*}\right)$ and fuzzy negativeideal solution $\left(A^{-}\right)$can be defined as (23).

$$
A^{*}=\left(\tilde{v_{1}^{*}}, \tilde{v}_{2}^{*}, \ldots, \tilde{v}_{n}^{*}\right), A^{-}=\left(\tilde{v_{1}^{-}}, \tilde{v_{2}^{-}}, \ldots, \tilde{v}_{n}^{-}\right)
$$

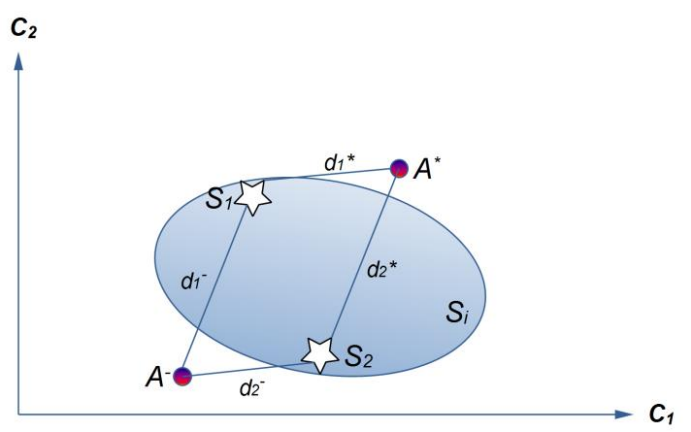

Fig. 4: The distance between positive and negative ideal solution for two alternatives

where

$$
\tilde{v}_{j}^{*}=\max \left\{v_{i j 2}\right\}, \tilde{v}_{j}^{-}=\min \left\{v_{i j 1}\right\}
$$

and the distance of each alternative from these two ideal points $\left(A^{*}\right.$ and $\left.A^{-}\right)$can be calculated by Euclid's formula (refer to (25) and (26))

$$
\begin{aligned}
& d_{i}^{*}=\sqrt{\sum_{j=1}^{n}\left(v_{i j-} v_{j}^{*}\right)^{2}} \\
& d_{i}^{-}=\sqrt{\sum_{j=1}^{n}\left(v_{i j-1} v_{j}^{-}\right)^{2}}
\end{aligned}
$$

8) The relative closeness of alternatives is defined by a closeness coefficient in order to determine the ranking order of alternatives:

$$
C C_{i}=\frac{d_{i}^{-}}{d_{i}^{*}+d_{i}^{-}}, i=1, \ldots, m
$$

This coefficient represents the distances of alternatives to the ideal points simultaneously. It is seen that if the alternative reaches $A^{*}$ or $S_{i}=A^{*}$ then $d_{i}^{*}=0$ and $C C_{i}=1$ and if the alternative reaches $A^{-}$or $S_{i}=A$ - then $d_{i}{ }^{-}$ $=0$ and $C C_{i}=0$. It means when the alternative goes toward $A^{*}$ or farther from $A^{-}$then $C C_{i}$ goes toward " 1 ". In addition, if the alternative goes toward $A^{-}$or farther from $A^{*}$ then $C C_{i}$ goes toward " 0 ".

\subsection{Output Results}

It is more realistic if the assessment overview of alternatives is described by linguistic variables in accordance to their closeness coefficient. Therefore, the interval $[0,1]$ could be divided into sub-divisions. Five sub-divisions are popular as indicated in Table 7 [19].

Table 7: Approval status of ranked alternatives

\begin{tabular}{cl}
\hline Closeness Coefficient & \multicolumn{1}{c}{ Assessment Status } \\
\hline $\mathrm{CCi} \in_{[0.0,0.2)}$ & Do not recommend \\
$\mathrm{CCi} \in_{[0.2,0.4)}$ & Recommend with high risk \\
$\mathrm{CCi} \in_{[0.4,0.6)}$ & Recommend with low risk \\
$\mathrm{CCi} \in_{[0.6,0.8)}$ & Approved \\
$\mathrm{CCi} \in_{[0.8,1.0]}$ & Approved and preferred \\
\hline
\end{tabular}

\section{The Architecture of Proposed DDS}

FGDM was programmed by $\mathrm{C \#}$ (pronounced see sharp) language. This is a multi-paradig m programming language encompassing imperative, declarative, functional, generic, object-oriented (class-based), and component-oriented programming disciplines and was developed by Microsoft with in the Dot NET in itiative. FGDM enables decision makers to log to the system from their offices, compare the importance of criteria and rate the alternatives with respect to criterion. This comes from a Microsoft SQL server which is a relational model database produced by Microsoft Co. The available options depend on the user. If the user is an administrator all features are active. When the other team members $\log$ on, there are two adjacent questionnaires, for pair-wise comparis on of criteria and for rating the alternatives with respect to each criterion both linguistical. To configure the program it is necessary to attach the FGDM database to the Microsoft SQL server. A common personal computer with 1 GB of RAM, 5 GB of disk space and connected to the local network is the minimum hardware requirements for running FGDM on client and server sides. 


\section{Conclusion}

Rapid and precise decision-making plays a major role in achieving objectives whether designated for individuals or organizations. This is due to accelerated globalization and advanced communication technology which creates a very dynamic competitive environ ment. It is visibly apparent that many famous companies have gone solvent as a result of ongoing failures in their decision-making performance. However, organizational decisions are related to different and often-conflicting criteria, and this type of situation increases the risks substantially. To subdue these difficulties, one common and simple solution is conducting face-to-face meetings with a diversity of involved parties in order to engage in dialogue and mutual negotiation. However, there are disadvantages with meetings such as the undesired influences of powerful people, ignoring the opinion of minor people, time and energy wasting and so forth. For these reasons virtual group decision making is an appropriate option. In this paper, we introduced a quantitative method to facilitate the decision making process and implemented it in a major optical company in Iran. The program requires different historical backgrounds of decision makers to be considered and exploits the fuzzy approach by applying linguistic values in order to assess criteria and alternatives. FGDM can be used for diverse multi-criterion decision making, these includ vagueness and uncertainties such as $R \& D$ project selection, employee selection etc...

\section{Acknowledgment}

The authors would like to acknowledge Sapa ElectroOptics and Laser Company, Isfahan, Iran for their comprehensive support and funding of this work. We would also like to thank Rayan Afzar-e-Novin Company, Isfahan, Iran for programming the (FGDM) software based on the proposed model.

\section{References}

[1] P., Tsvetinov and L. Mikhailov, "Reasoning under uncertainty during pre-negotiations using a fuzzy AHP", 7th International Conference on Business Information Systems, Poznań, Poland, 21-23 April 2004

[2] E. Forman and M.A Selly, Decision By Objectives, How to convince others that you are right, George Washington University, 2001, pp. 1

[3] A. Thatcher and A. De La Cour, "Small group decision-making in face-to-face and computermediated environments: the role of personality", Behaviour and Information Technology, vol. 22, no.3, pp. 203-218, 2003

[4] V. Chichernea1, "The decision support systems for the information society (i-Society)", Journal of
Information Systems and Operations Management, vol. 4, no. 2, pp. 58-92, 2010

[5] J. Fjermestad, "Virtual group strategic decision making using structured conflict and consensus approaches", International Journal of eCollaboration vol. 1, no. 1, pp.43-61, 2005

[6] R.E. Bellman and L. Zadeh," "Decision making in a fuzzy environment", Management Science, vol. 17, no. 4, 1970

[7] Yi W. Hung, T. Gwo-Hshiung and C. Yi Hsuan, "A fuzzy MCDM approach for evaluating banking performance based on Balanced Scorecard, Expert Systems with Applications vol.36, pp. 1013510147, 2009

[8] L.A. Zadeh, "Fuzzy sets", Information and Control, no.8, pp. 338-353, 1956

[9] T.Y. Hsieh, S.T. Lu and G.H Tzeng, "Fuzzy MCDM approach for planning and design tenders selection in public office build ings", International Journal of Project Management, vol. 22, no.7, pp. 573-584, 2004

[10] T. Saaty, The analytic hierarchy process, McGrawHill, New York., 1980

[11] C. H. Cheng, K.L. Yang and C.L. Hwang, "Evaluating attack helicopters by AHP based on linguistic variable weight", European Journal of Operational Research, no. 116, pp. 423-435, 1999

[12] C. Kahraman, U. Cebeci and Z. Ulukan, "Multi criteria supplier selection using fuzzy AHP", Logistic Information Management, vol. 16, no. 6, pp. 382-394, 2003

[13] H. M. Hsu, and C. T. Chen, "Aggregation of fuzzy opinions under group decision making”, Fuzzy Sets and System, no. 79, pp. 279-285, 1996

[14] R .L. Keeney and C.W. Kirkwood, "Group decision making Using Cardinal Social Welfare Functions, Management Science 22 (4), 430-437, 1975

[15] D. C. Kingsley and T. C. Brown, "Preference uncertainty, preference learning, and paired comparison experiments", Land Economics, vol. 86, no. 3, pp. 530-544, August 2010

[16] J. Sheth, "A model of industrial buyer behavior", Journal of Marketing, no. 37, pp. 50-56, 1973

[17] A.F. Guneri, A..Yucel and G. Ayyildiz, "An integrated fuzzy - lp approach for a supplier selection problem in supply chain management", Expert Systems with Applications, no. 36, pp. 9223-9228, 2009

[18] S.H. Tsaur, T.Y. Chang and C.H. Yen, "The evaluation of airline service quality by fuzzy MCDM", Touris m Management, no. 23, pp. 107115,2002 
[19] CT. Chen, CT. Lin and SF. Huang, "A fuzzy approach for supplier evaluation and selection in supply chain management", International Journal of Production Economics, vol. 102, pp. 289-301, 2006

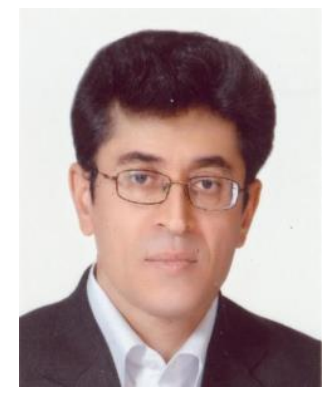

Bahram Izadi received his B.S in Applied Physics from University of Isfahan, Iran in 1986. He completed his Master in Business Administration at the same university in 2009 and passed entrance exams for PHD of Marketing Management at University of Isfahan in the same year. $\mathrm{He}$ is currently working on his dissertation in the area of E-market segmentation. His area of interest includes E-Business and E-Marketing.

Dr. Saeedeh Ketabi is professor of Operation Research (OR) in Management Department, University of Isfahan, IRAN. She received her B.S in Applied Mathematics from Tehran University in 1987 and her Master in Operation Research from Isfahan University of Technology Isfahan, IRAN. She also received her PHD from University of Adelaide, Australia. She possesses an experience of more than 20 years in the field of OR teaching and research. She has published nearly 50 papers in international and national journals and conferences. She especially interested in Operations Research applications in health care.

How to cite this paper: Bahram Izadi, Saeedeh Ketabi,"Developing a Virtual Group Decision Support System Based on Fuzzy Hybrid MCDM Approach", International Journal of Information Technology and Computer Science(IJITCS), vol.5, no.2, pp.28-35, 2013.DOI: 10.5815/ijitcs.2013.02.03 